\title{
Distinct Patterns of Tryptophan Maintenance in Tissues during Kynurenine Pathway Activation in Simian Immunodeficiency Virus-Infected Macaques
}

\author{
Julia L. Drewes, Joshua D. Croteau, Erin N. Shirk, Elizabeth L. Engle, M. C. Zink ${ }^{*}$ and \\ David R. Graham*
}

Department of Molecular and Comparative Pathobiology, Johns Hopkins University School of Medicine, Baltimore, MD, USA

OPEN ACCESS

Edited by:

Maritza Romero,

Augusta University, USA

Reviewed by:

Ali M. Harandi,

University of Gothenburg, Sweden

Matteo A. Russo,

Sapienza University, Italy

Andrew L. Mellor,

Georgia Health Sciences University,

USA

*Correspondence:

M. C. Zink

mczink@jhmi.edu;

David R. Graham

dgraham@jhmi.edu

Specialty section:

This article was submitted to

Nutritional Immunology,

a section of the journal

Frontiers in Immunology

Received: 21 September 2016 Accepted: 01 December 2016 Published: 19 December 2016

Citation:

Drewes JL, Croteau JD, Shirk EN,

Engle EL, Zink MC and Graham DR

(2016) Distinct Patterns of

Tryptophan Maintenance in Tissues

during Kynurenine Pathway Activation

in Simian Immunodeficiency

Virus-Infected Macaques.

Front. Immunol. 7:605.

doi: 10.3389/fimmu.2016.00605
Induction of the kynurenine pathway (KP) of tryptophan (TRP) catabolism has been proposed to contribute to $T$ cell dysfunction during human/simian immunodeficiency virus (SIV) infection via depletion of local TRP levels and production of immunomodulatory KP metabolites. However, while changes in TRP and KP metabolites have been observed in plasma, their levels in lymphoid tissues and levels of enzymes downstream of indoleamine 2,3-dioxygenase (IDO1) have been relatively unexplored. We used our SIV-infected pigtailed macaque model to analyze longitudinal changes in KP metabolites and enzymes by gas chromatography/mass spectrometry and NanoString nCounter gene expression analysis, respectively, in spleen and blood compared to changes previously established in brain and CSF. We found that TRP levels were remarkably stable in tissue sites despite robust depletion in the circulating plasma and CSF. We also demonstrated that intracellular TRP reserves were maintained in cultured cells even in the presence of depleted extracellular TRP levels. Kynurenine (KYN), 3-hydroxykynurenine, quinolinic acid, and the KP enzymes all displayed highly divergent patterns in the sites examined, though IDO1 expression always correlated with local KYN/TRP ratios. Finally, we demonstrated by fluorescence-activated cell sorting that myeloid dendritic cells and cells of monocytic lineage were the highest producers of IDO1 in chronically infected spleens. Overall, our study reveals insights into the tissue-specific regulation of KP enzymes and metabolites and, in particular, highlights the multiple mechanisms by which cells and tissues seek to prevent TRP starvation during inflammation.

Keywords: SIV, HIV, immunosuppression, tryptophan, kynurenine, IDO1, spleen

Abbreviations: APC, antigen-presenting cell; ART, anti-retroviral therapy; cART, combination anti-retroviral therapy; D-1MT, 1-methyl-D-tryptophan; DC, dendritic cell; FACS, fluorescence-activated cell sorting; GCMS, gas chromatography mass spectrometry; GCN2, general control non-derepressible 2, also known as EIF2AK4; HAAO, 3-hydroxyanthranilate3,4-dioxygenase, also known as 3HAO; HIV, human immunodeficiency virus; IDO1, indoleamine 2,3-dioxygenase; IFN, interferon; KMO, kynurenine 3-monooxygenase, also known as kynurenine 3-hydroxylase; KP, kynurenine pathway; KYN, kynurenine; KYN/TRP, kynurenine/tryptophan ratio; KYNU, kynureninase; $\mathrm{mDC}$, myeloid dendritic cell; MNC, mononuclear cell; NAD+, nicotinamide adenine dinucleotide; pDC, plasmacytoid dendritic cell; PBMC, peripheral blood mononuclear cell; QPRT, quinolinate phosphoribosyltransferase; QUIN, quinolinic acid; SIV, simian immunodeficiency virus; SOCS3, suppressor of cytokine signaling 3; TRP, tryptophan; TTS, tryptophanyl tRNA synthetase; TYR, tyrosine; 3HANA, 3-hydroxyanthranilic acid; 3HK, 3-hydroxykynurenine. 


\section{INTRODUCTION}

Induction of the kynurenine pathway (KP) of tryptophan (TRP) catabolism is thought to play a major role in immune dysfunction in human immunodeficiency virus (HIV)-infected individuals, even those on combination anti-retroviral therapy (cART) (1-8). While the KP is an important source of the cellular cofactor NAD+, TRP is a rare essential amino acid, and small changes in TRP metabolism can have major consequences. For example, reducing extracellular TRP levels suppresses proliferation of actively dividing cells $v i a$ accumulation of uncharged TRP-tRNAs and subsequent activation of the GCN2 stress kinase pathway (9). This mechanism could suppress patients' $\mathrm{T}$ cell responses to HIV or secondary opportunistic infections. In addition to the consequences of TRP depletion, increased TRP catabolism down the KP also leads to generation of metabolites that have immunomodulatory capabilities, which include prevention of $\mathrm{T}$ cell proliferation [kynurenine (KYN) and picolonic acid] (10); conversion of naïve $\mathrm{T}$ cells or proinflammatory Th17 cells into regulatory $\mathrm{T}$ cells following interactions at the aryl hydrocarbon receptor, which may increase susceptibility to opportunistic infections at mucosal surfaces [KYN and 3-hydroxy anthranilic acid (3HANA)] $(2,11)$; and direct apoptosis of activated $\mathrm{T}$ cells (3HANA and cinnabarinic acid) $(12,13)$.

Thus, both the generation of immunosuppressive KP metabolites and depletion of TRP during HIV/simian immunodeficiency virus (SIV) infection could contribute to peripheral HIV pathogenesis. However, several key questions remain unanswered in the field. For example, while TRP and KP metabolites in the blood of HIV-infected patients have been extensively measured $(1,2,5-8,14)$, whether or not these measurements in the circulation accurately reflect changes occurring in lymphoid tissues is unknown, leading to assumptions that this is a major mechanism of suppression in lymphoid tissues. Additionally, while expression of the rate-limiting enzyme indoleamine 2,3-dioxygenase 1 (IDO1) has been repeatedly examined in the context of HIV/SIV infection, the regulation of downstream enzymes of the KP has been relatively unexplored.

To explore these questions, we measured the longitudinal kinetics of KP enzymes and metabolites by multiplexed mRNA (Nanostring nCounter) and GC-MS/MS assays in spleen and plasma from an accelerated pigtailed macaque model of HIV infection in which animals develop clinical symptoms of AIDS within 3 months (15). Our results show that individual cells (macrophages) and tissues (spleen) actively maintain internal TRP levels while depleting extracellular and circulating (plasma) TRP during KP activation. These data suggest that immunosuppressive effects of IDO1 in tissues are more likely a result of immunomodulatory KP metabolites than TRP starvation, representing a potential paradigm shift in our understanding of IDO1-mediated immunosuppression in HIV pathogenesis.

\section{MATERIALS AND METHODS}

\section{Animals}

Macaque experiments performed in this study utilized archived samples from juvenile pigtailed macaques (Macaca nemestrina) that were either mock inoculated or inoculated intravenously with a neurotropic clone (SIV/17E-Fr) and an immunosuppressive swarm (SIV/DeltaB670), as previously described (16). Animals were euthanized during various stages of disease: acute (7, 10, 14 days p.i.), asymptomatic ( $21 \mathrm{dpi})$, and chronic infection $(35,42,56$, and $84 \mathrm{dpi})$. Animals euthanized prior to their planned euthanasia date due to presentation of clinical symptoms (17) were grouped with $84 \mathrm{dpi}$ animals as SIV terminal ("T" in figures). Blood draws were taken prior to infection as well as on days $7,10,14,21,28$, and every 2 weeks thereafter postinfection. All animals were euthanized in accordance with federal guidelines and institutional policies. Macaques were perfused with sterile PBS while under deep anesthesia, and tissues were collected and flash frozen. All animal studies were approved by the Johns Hopkins Animal Care and Use Committee, and all animals were humanely treated in accordance with federal guidelines and institutional policies.

\section{Macrophage Cell Culture}

Pigtailed macaque peripheral blood mononuclear cells (PBMCs) were cultured in macrophage differentiation media (MDM) containing DMEM supplemented with 20\% human AB serum (Gemini Bio Products), $50 \mathrm{ng} / \mathrm{mL}$ recombinant human macrophage colony-stimulating factor (R\&D Systems), $2 \mathrm{mM}$ sodium pyruvate (Sigma), $2 \mathrm{mM}$ L-glutamine (Life Technologies), $1 \mathrm{mM}$ HEPES buffer (Life Technologies), and $20 \mu \mathrm{g} / \mathrm{mL}$ gentamicin (Gibco) for 7 days until mature macrophages were visible. Macrophages were then washed $3 \times$ with PBS and switched to MDM with $10 \%$ human $\mathrm{AB}$ serum. Twenty-five nanograms per milliliter of rhesus IFN $\gamma$ (R\&D Systems) or $400 \mathrm{U} / \mathrm{mL}$ human IFN $\beta 1$ a (PBL Interferon Source) were added in duplicate wells for each time point. After $0,24,48$, and $72 \mathrm{~h}$, supernatants were saved for KP metabolite analysis, and cells were washed and then harvested with gentle scraping for KP metabolite and IDOI gene expression analysis. Metabolites were normalized to controls at each time point as well as to tyrosine (TYR), which does not change during HIV infection (18), to control for minor variations in cell number that could affect metabolism.

\section{Metabolite Extraction from Spleen}

A 3-mm punch was taken from perfused, snap-frozen spleen tissue from SIV-infected pigtailed macaques. Punches were weighed and diluted $1 / 20$ (weight/volume) with cold $0.1 \%$ ascorbic acid and sonicated with a tip sonicator three to five times at $70 \%$ amplitude for $5 \mathrm{~s}$ each, in batches on ice. Residual debris was removed by brief tabletop centrifugation prior to extraction of metabolites. On ice, $50 \mu \mathrm{L}$ of spleen homogenates (of the original $1 / 20$ homogenates for metabolite measurement, or diluted further for a final of $1 / 2,000$ in $0.1 \%$ ascorbic acid for amino acid measurement) were spiked with $50 \mu \mathrm{L}$ of a solution containing the following heavy standards: $\left[{ }^{2} \mathrm{H}_{5}\right]$ TRP $(1 \mu \mathrm{M}, \mathrm{CDN}$ Isotopes, QC, Canada), $\left[{ }^{2} \mathrm{H}_{2}\right]$ TYR $(1 \mu \mathrm{M}, \mathrm{CDN}$ Isotopes, QC, Canada), $\left[{ }^{2} \mathrm{H}_{6}\right] \mathrm{KYN}(5 \mu \mathrm{M}$, custom synthesis from Sigma-Aldrich Isotec), and $\left[{ }^{2} \mathrm{H}_{3}\right]$ quinolinic acid $(0.05 \mu \mathrm{M}$, custom synthesis from Synfine, ON, Canada). Fifty microliters of ice cold acetone were added to homogenates and samples were centrifuged at 20,000 g for $5 \mathrm{~min}$ to precipitate protein. Eighty percent $(120 / 150 \mu \mathrm{L})$ of 
the acetone supernatant was transferred to a new microcentrifuge tube, to which $50 \mu \mathrm{L}$ of a 2:5 ratio methanol:chloroform was added. Samples were centrifuged at $20,000 \mathrm{~g}$ for $10 \mathrm{~min}$, and $60 \%(80 / 134 \mu \mathrm{L})$ of the aqueous layers were transferred to glass vials. The aqueous solution was dried and then derivatized with $120 \mu \mathrm{L}$ of 2,2,3,3-pentafluoro-1-propanol (Sigma-Aldrich) and $135 \mu \mathrm{L}$ of pentafluoropropionic anhydride (Sigma-Aldrich) by heating at $75^{\circ} \mathrm{C}$ for $30 \mathrm{~min}$. Derivatized samples were dried and stored at $-80^{\circ} \mathrm{C}$.

\section{Metabolite Extractions from Plasma and Macrophage Cell Culture Supernatants}

Metabolite extractions from plasma and cell culture supernatants were identical to spleen with the following modifications: for plasma samples, $2 \mu \mathrm{L}$ of cell-free plasma were diluted $1 / 25$ with $0.1 \%$ ascorbic acid in a final volume of $50 \mu \mathrm{L}$ for metabolite and amino acid measurements. For cell culture supernatants, cell-free supernatants were diluted $1 / 2$ in $0.2 \%$ ascorbic acid for metabolites and $1 / 100$ in $0.1 \%$ ascorbic acid for amino acids, all in a final volume of $50 \mu \mathrm{L}$. The heavy standard mixture for plasma and cell culture supernatant matrices required higher concentrations for two metabolites: $15 \mu \mathrm{M}$ instead of $5 \mu \mathrm{M}$ for $\left[{ }^{2} \mathrm{H}_{6}\right] \mathrm{KYN}$, and $0.2 \mu \mathrm{M}$ instead of $0.05 \mu \mathrm{M}$ for $\left[{ }^{2} \mathrm{H}_{3}\right]$ quinolinic acid. All other heavy standards were kept at $1 \mu \mathrm{M}$. Acetone extraction supernatants were dried down directly on a speedvac without methanol/chloroform extraction and then derivatized as above.

\section{Metabolite Extraction from In Vitro Macrophage Cells}

Macrophage cell pellets were resuspended in $100 \mu \mathrm{L}$ of $0.1 \%$ ascorbic acid and sonicated $2 \times$ for $3 \mathrm{~s}$ each at $30 \%$ amplitude with a tip sonicator on ice. Fifty microliters of this homogenate were used as the starting material for intracellular amino acid and metabolite measurements. The heavy standard concentrations were identical to those used for plasma and cell culture supernatant samples. The acetone precipitation, methanol/chloroform extraction, and derivatization for the macrophage cell pellets were otherwise performed in an identical manner to the protocol used for spleen homogenates.

\section{GC/MS/MS Analysis of Amino Acids and KP Metabolites}

Dried samples were resuspended in $50 \mu \mathrm{L}$ ethyl acetate, with the exception of the in vitro macrophage lysates, which were resuspended in a smaller volume of $25 \mu \mathrm{L}$ to maximize signal. One microliter, or $2 \mu \mathrm{L}$ for the in vitro macrophage lysates, was injected in pulsed, splitless mode into an Agilent 7890A GC coupled to a 7000 MS/MS equipped with an Agilent 7693A autosampler operated in electron capture negative ionization mode, as previously described (19). The multiple reaction monitoring transitions used in this study were based on transitions initially described by Eckstein et al. (20) and have been subsequently optimized. The transitions for the derivatized compounds were as follows: TRP $\mathrm{Q} 1=608.2, \mathrm{Q} 3=270, \mathrm{CE}=5$, retention time $(\mathrm{RT})=13.1 \mathrm{~min}$; $\left[{ }^{2} \mathrm{H}_{5}\right] \mathrm{TRP} \mathrm{Q} 1=613.2, \mathrm{Q} 3=351, \mathrm{CE}=20, \mathrm{RT}=13.1 \mathrm{~min}$; TYR
$\mathrm{Q} 1=585.2, \mathrm{Q} 3=268, \mathrm{CE}=20, \mathrm{RT}=10.9 \mathrm{~min} ;\left[{ }^{2} \mathrm{H}_{2}\right] \mathrm{TYR}$ $\mathrm{Q} 1=587.2, \mathrm{Q} 3=436.9, \mathrm{CE}=20, \mathrm{RT}=10.9 ; \mathrm{KYN} \mathrm{Q} 1=612$, $\mathrm{Q} 3=442, \mathrm{CE}=10, \mathrm{RT}=13.0 \mathrm{~min} ;\left[{ }^{2} \mathrm{H}_{6}\right] \mathrm{KYN} \mathrm{Q} 1=618, \mathrm{Q} 3=447$, $\mathrm{CE}=10, \mathrm{RT}=13.0 \mathrm{~min}$; QUIN Q1 = 431.0, Q3 = 298.0, collision energy $(\mathrm{CE})=10 \mathrm{~V}, \mathrm{RT}=9.4 \mathrm{~min} ;\left[{ }^{2} \mathrm{H}_{3}\right]$ QUIN Q1 = 434.0, $\mathrm{Q} 3=301.0, \mathrm{CE}=10 \mathrm{~V}, \mathrm{RT}=9.4 \mathrm{~min} ; 3 \mathrm{HK} \mathrm{Q} 1=630, \mathrm{Q} 3=219$, $\mathrm{CE}=15, \mathrm{RT}=12.9 \mathrm{~min}$. Data were analyzed in a blinded fashion using the Agilent MassHunter software, Build B.04 or B.05. Samples were injected in a randomized order to minimize experimental bias. Each sample was injected at least twice. The average of the peak areas from replicate injections were normalized to the average of the heavy standards for each respective compound. $3 \mathrm{HK}$ was the only compound for which we did not have a matching heavy standard; thus, we normalized $3 \mathrm{HK}$ to $\left[{ }^{2} \mathrm{H}_{6}\right]$ KYN because of their similar ionization properties. These values were fit to the matrix-spiked light standard curves for each compound based on the standard addition method.

\section{Flow Cytometry}

Single-cell suspensions of spleen were obtained by mechanical disruption and passage through a $100 \mu \mathrm{M}$ filter. Cells were then stained for fluorescence activated cell sorting (FACS) of dendritic, monocytic, and $\mathrm{T}$ cell populations, examined on a FACSAriaII (BD) at the SKCCC Flow Cytometry Core, or were stained with separate panels for extensive flow cytometry phenotyping on an LSRFortessa (BD). Representative gating is shown in Figures S1 and S2 in Supplementary Material, respectively, and a list of macaque antibody clones is provided in Table S1 in Supplementary Material. Data were analyzed using the FACSDiVa 6.1.3 (BD) or FlowJo (FlowJo) software.

\section{qRT-PCR}

RNA was extracted using the RNeasy Plus Mini kit (Qiagen). RNA was reverse transcribed using the High Capacity cDNA Kit (Invitrogen Life Technologies; FACS-sorted spleen cells) or SuperScript III (Invitrogen Life Technologies; PBMCs and in vitro macrophages) on a thermal cycler: $25^{\circ} \mathrm{C}$ for $10 \mathrm{~min}, 37^{\circ} \mathrm{C}$ for $120^{\circ} \mathrm{C} \mathrm{min}$, and $85^{\circ} \mathrm{C}$ for $5 \mathrm{~min}$.

Because of the small amount of starting material in the sorted cells, cDNA from FACS samples were pre-amplified using the TaqMan PreAmp Master Mix (Life Technologies) with a pooled assay of $0.2 \times$ primers for GAPDH and IDO1 on a thermal cycler: $95^{\circ} \mathrm{C}$ for $10 \mathrm{~min}, 95^{\circ} \mathrm{C}$ for $15 \mathrm{~s}, 60^{\circ} \mathrm{C}$ for $4 \mathrm{~min}$, with steps $2-3$ repeated 14 times. Preamplified cDNA was then diluted $1 / 20$ and amplified again using the TaqMan Gene Expression Assay (Life Technologies).

All other cDNA samples were amplified using the Multiplex NoRox PCR Mix (Qiagen): $50^{\circ} \mathrm{C}$ for $2 \mathrm{~min}, 95^{\circ} \mathrm{C}$ for $10 \mathrm{~min}$, $95^{\circ} \mathrm{C}$ for $15 \mathrm{~s}, 60^{\circ} \mathrm{C}$ for $1 \mathrm{~min}$, with steps $3-4$ repeated 40 times. GAPDH VIC primer/probe was obtained from Life Technologies (Rh02621745_g1). $18 S$ and IDO1 primer/probes were custom synthesized from Integrated DNA Technologies: IDO1 (5' -TGCTTTGACGTCCTGCTGG, 5' -TTCCTGTGAGCTGGT GGCA, and 5' -TXR-ATGCTGCTCAGTTCCTCCAGGACA IAbRQs); $18 \mathrm{~S}$ rRNA (5'-TAGAGGGACAAGTGGCGTTC, 5'-CGCTGAGCCAGTCAGTGT, and 5'-Cy5-AGCAATAACA GGTCTGTGATG-BHQ2). Results were analyzed via the $2^{-\Delta \Delta \mathrm{Ct}}$ 
method, with similar results following normalization to either $18 S$ or GAPDH.

\section{NanoString Gene Expression Analysis}

As part of a larger collaborative project, $200 \mathrm{ng}$ of RNA from spleens from 58 animals euthanized at various time points postinfection were analyzed via a custom NanoString CodeSet for 116 macaque genes based on rhesus macaque (Macaca mulatta) and human sequences, as previously described (21). RNA was harvested from 3-mm punches of snap-frozen macaque spleen tissue by homogenization in RNA STAT-60 (Isotex Diagnostics) in lysing matrix tubes followed by RQ1 DNase treatment (Promega) for $1 \mathrm{~h}$ at $37^{\circ} \mathrm{C}$ and purification with the miRVana Kit (Invitrogen). Target sequences used in this study are listed in Table S2 in Supplementary Material. RNA was hybridized for $16 \mathrm{~h}$ using the CodeSet and analyzed using the nCounter Digital Analyzer. Data were normalized to the geometric mean of six spiked-in positive controls to correct for assay efficiency. The background signal threshold was defined as the average of eight spiked-in negative controls +2 SDs following positive control correction, a threshold of 30 counts. None of the genes in this study had a majority of counts below this threshold. As no single housekeeping gene has been proven to be consistently expressed across different cell types, cell maturation states, tissue types, or disease models (22-26), we performed Kruskal-Wallis nonparametric analyses of variance on all positive control normalized genes to find the most stably expressed genes across the spleen samples $(22,27)$. We found that the markers CD19, GEM, STK25, and CCS were the least varying genes between infection groups (Kruskal-Wallis $p$-values $=0.203,0.170,0.121$, and 0.111 , respectively). The geometric mean of these four genes was used to normalize the positive control corrected data (26). Trends in SIV viral load and IDO1 mRNA expression in spleen were independently verified for subsets of the animals by qRT-PCR.

Samples from colon and ileum from 8 additional pigtailed macaques ( 3 procedural controls and 5 chronically infected animals euthanized at approximately 84 days postinfection) were analyzed in a separate Nanostring CodeSet panel involving 249 macaque genes based on M. mulatta and human sequences, as previously described (28). RNA was extracted from 3-mm punches of snap-frozen macaque colon and ileum tissue in a manner identical to the spleen above. Colon and ileal RNA were supplemented with SUPERase-In RNase Inhibitor for long-term storage ( $1 \mathrm{U} / \mu \mathrm{L}$ final concentration; Life Technologies). Target sequences used for the colon and ileum tissue in this study are listed in Table S3 in Supplementary Material. Colon and ileum transcript RNA data for the five KP genes of interest were normalized to positive control corrected data and then to the geometric mean of four housekeeping genes that were not significantly different between infection groups in the colon or ileum by Kruskal-Wallis: HPRT1, RPL13A, RPS9, and SDHA.

\section{Statistical Analyses}

Spleen metabolite data were analyzed by Mann-Whitney test to compare peak values during acute infection (the time point with the highest median between days 0 and 14 p.i. for each metabolite, or nadir for TRP), values during asymptomatic infection (day 21 p.i.), and all values during chronic infection (between days 35 p.i. and terminal) against uninfected controls. $p$-values were Bonferroni adjusted for multiple comparisons.

For plasma metabolites, Wilcoxon signed-rank tests were performed on the fold change data to determine whether the peak (nadir for TRP) for each animal during acute infection, or median values for each animal during asymptomatic and chronic infection, were significantly different from their respective preinfection values (set as the theoretical value of 1 ). $p$-values were Bonferroni adjusted for multiple comparisons.

Macrophage metabolites and IDO1 enzyme expression data following interferon stimulation were analyzed by Friedman's test for non-parametric, repeated measures data. Longitudinal spleen Nanostring nCounter mRNA data were analyzed by Kruskal-Wallis test followed by Benjamini-Hochberg false discovery rate corrections to account for the number of genes examined in the assay. Transcripts that had a significant overall Kruskal-Wallis $p$-value $<0.05$ following Benjamini-Hochberg correction underwent Mann-Whitney tests as described above for spleen metabolites. Colon and ileum Nanostring nCounter data comparing uninfected and terminally infected animals were analyzed by Mann-Whitney test.

Multiple comparison corrections were performed in Microsoft Office 2011 Excel. GraphPad Prism 6.0 was used to perform all other statistical analyses.

\section{RESULTS}

\section{Longitudinal Kinetics of KP Metabolites in Plasma during SIV Infection}

We first measured KP metabolites in plasma sampled longitudinally from seven macaques following SIV infection. Baseline levels are listed in Table S4 in Supplementary Material. Plasma TRP displayed an immediate drop during acute infection (Figure 1A, $p=0.048$ nadir at day 10 p.i. compared to preinfection values), which was sustained throughout asymptomatic and chronic infection, significantly so in the latter $(p=0.048)$.

Levels of KYN, the first major TRP metabolite in the KP, inversely mirrored TRP, peaking significantly at day 7 p.i. (Figure 1B, $p=0.048$ ), recovering to baseline by day 14 p.i., and then resurging during asymptomatic infection $(p=0.048)$. In contrast, $3 \mathrm{HK}$, the downstream metabolite of $\mathrm{KYN}$, paralleled TRP and was significantly below preinfection values during acute and asymptomatic infection (Figure 1C, $p=0.048$ for both analyses). The drop in $3 \mathrm{HK}$ levels did not reflect a lack of downstream KP activity, however, as levels of the terminal KP metabolite QUIN were significantly elevated above baseline during acute and asymptomatic infection (Figure 1D, $p=0.048$ for both comparisons). The KYN/TRP ratio was significantly elevated throughout all three phases of infection compared to preinfection values (Figure 1E, $p=0.048$ for all phases).

Serum albumin, which binds $>90 \%$ of total TRP in the blood, was also measured longitudinally in two of the animals. A loss in total TRP concentrations along with stable albumin levels would result in decreased free TRP available for cellular uptake, as cells can only access unbound, free TRP. However, consistent 

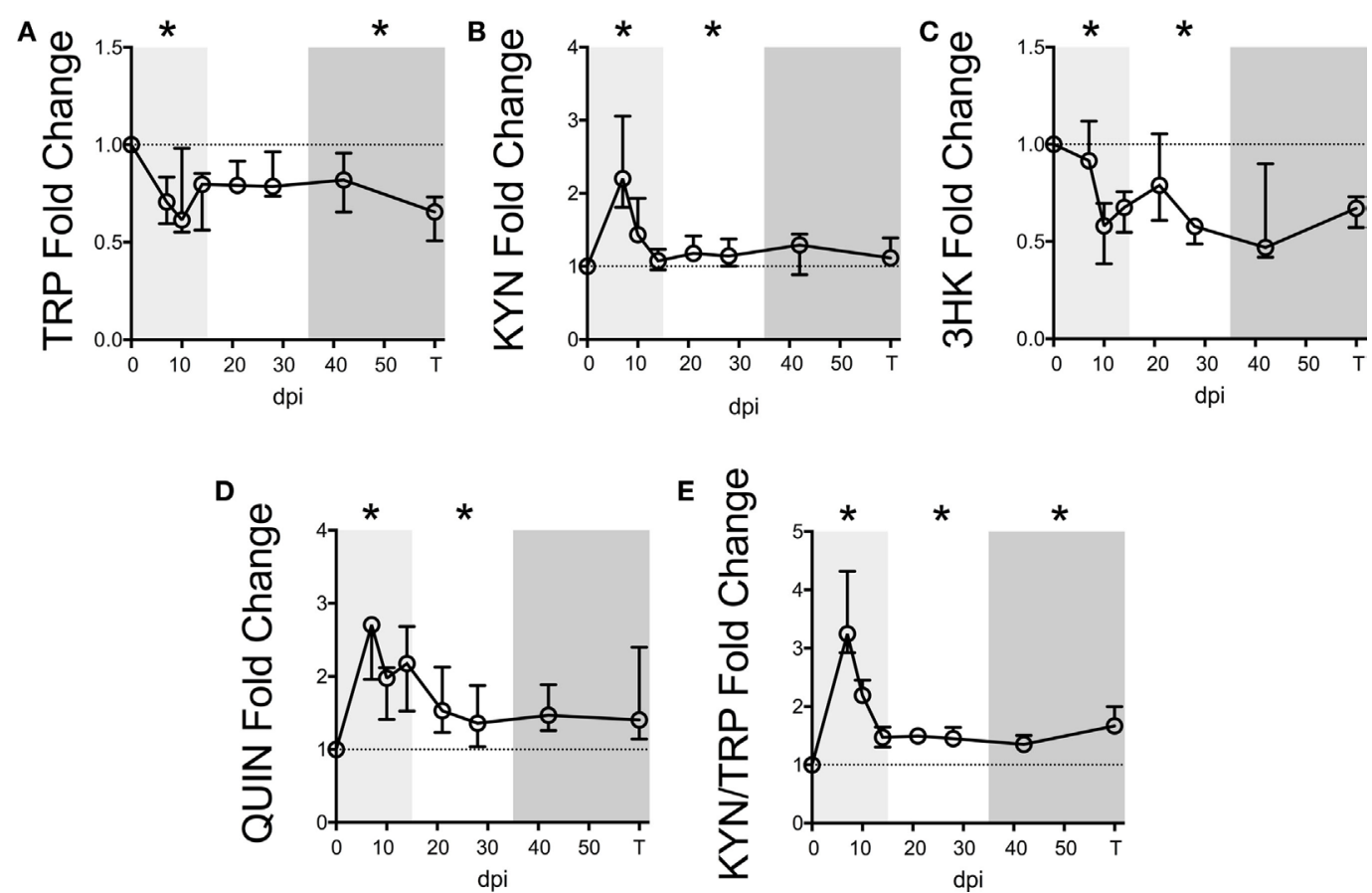

FIGURE 1 | Longitudinal kynurenine pathway metabolites in plasma during SIV infection of pigtailed macaques. Seven pigtailed macaques were followed longitudinally, with three plasma samples taken prior to infection and seven samples taken postinfection at days 7, 10, 14, 21, 28, 42, and terminally (approximately 84 dpi). Plasma samples were analyzed for levels of (A) TRP, (B) KYN, (C) 3HK, (D) QUIN, and (E) KYN/TRP ratios. Data are represented as median fold change over the average of the preinfection samples for each animal. Error bars represent interquartile ranges. Dotted lines represent the median of preinfection values. Light gray shading represents the acute phase of infection ( $0-14 \mathrm{dpi})$, and dark gray shading represents the chronic phase of infection ( $\geq 35 \mathrm{dpi})$ in our model. Asterisks $\left(^{*}\right)$ indicate whether the peak for each animal during acute infection or median values for each animal during asymptomatic and chronic infection was significantly different $(p<0.05)$ from respective preinfection values by Wilcoxon signed-rank test followed by Bonferroni correction.

with reports of decreased albumin levels in patients (29-31), we found that serum albumin levels decreased longitudinally alongside total TRP in these two animals, potentially minimizing the impact on free TRP levels (Figure S3 in Supplementary Material).

\section{Longitudinal Kinetics of KP Metabolites in Spleens of SIV-Infected Macaques}

To determine whether TRP and KP metabolites were similarly altered in lymphoid tissue during the course of SIV infection, we harvested metabolites from archived spleens from 58 animals euthanized at various points throughout infection. Exact numbers of animals per time point are listed in Table S5 in Supplementary Material.

Notably, TRP levels did not significantly change at any time point during infection in the spleen (Figure 2A). However, an acute (not significant) drop in median spleen TRP levels at day 4 p.i. from approximately 100 to $70 \mu \mathrm{M}$ corresponded with an acute increase in KYN levels of approximately $30 \mu \mathrm{M}$ at this time point that was significant (Figure $2 \mathrm{~B}, p=0.012$ ), indicating a nearly perfect 1:1 turnover of TRP into KYN. KYN returned to baseline by day 10 p.i. and remained at control levels for the remainder of infection. Levels of the downstream metabolites $3 \mathrm{HK}$ and QUIN peaked slightly later than KYN (Figures 2C,D, $p=0.012$ at day 7 p.i. for both $3 \mathrm{HK}$ and QUIN), consistent with a temporal progression of degradation down the QUIN axis of the KP during infection. Spleen KYN/TRP ratios were similarly elevated during acute infection (Figure 2E, $p=0.012$ at the peak at day 4 p.i.), but actually dropped below baseline during asymptomatic infection due to the apparent hyper-recovery of TRP levels at day 21 p.i. ( $p=0.012$ for KYN/TRP ratios at day 21 p.i.). However, neither TRP nor any of the KP metabolites or KYN/TRP ratios underwent any significant changes chronically in the spleen (day 35 p.i. and onward). In comparison to the plasma, the spleen therefore displayed divergent responses. In particular, plasma KYN/TRP ratios, which have been used to predict tissue KP activation, were found to overestimate tissue KYN/TRP induction.

\section{Systems-Wide Comparison of KP Changes during SIV Infection}

To further understand the dynamics of KP flux occurring at different sites in the body, we compared KP metabolites in plasma and spleen with our previous data from CSF and striatal brain tissue from these animals (32) (Figures 3A-E). The striatal region (a component of the basal ganglia) was chosen because it harbors abundant viral replication and demonstrates hallmarks of HIVassociated neurological disease in both HIV and SIV infection, likely in part due to the striatum's susceptibility to the neurotoxic KP metabolites $3 \mathrm{HK}$ and QUIN, as well as other sources of oxidative stress and neurotoxicity (33-36). Comparing the brain vs. the spleen could thus provide a glimpse into commonalities or 

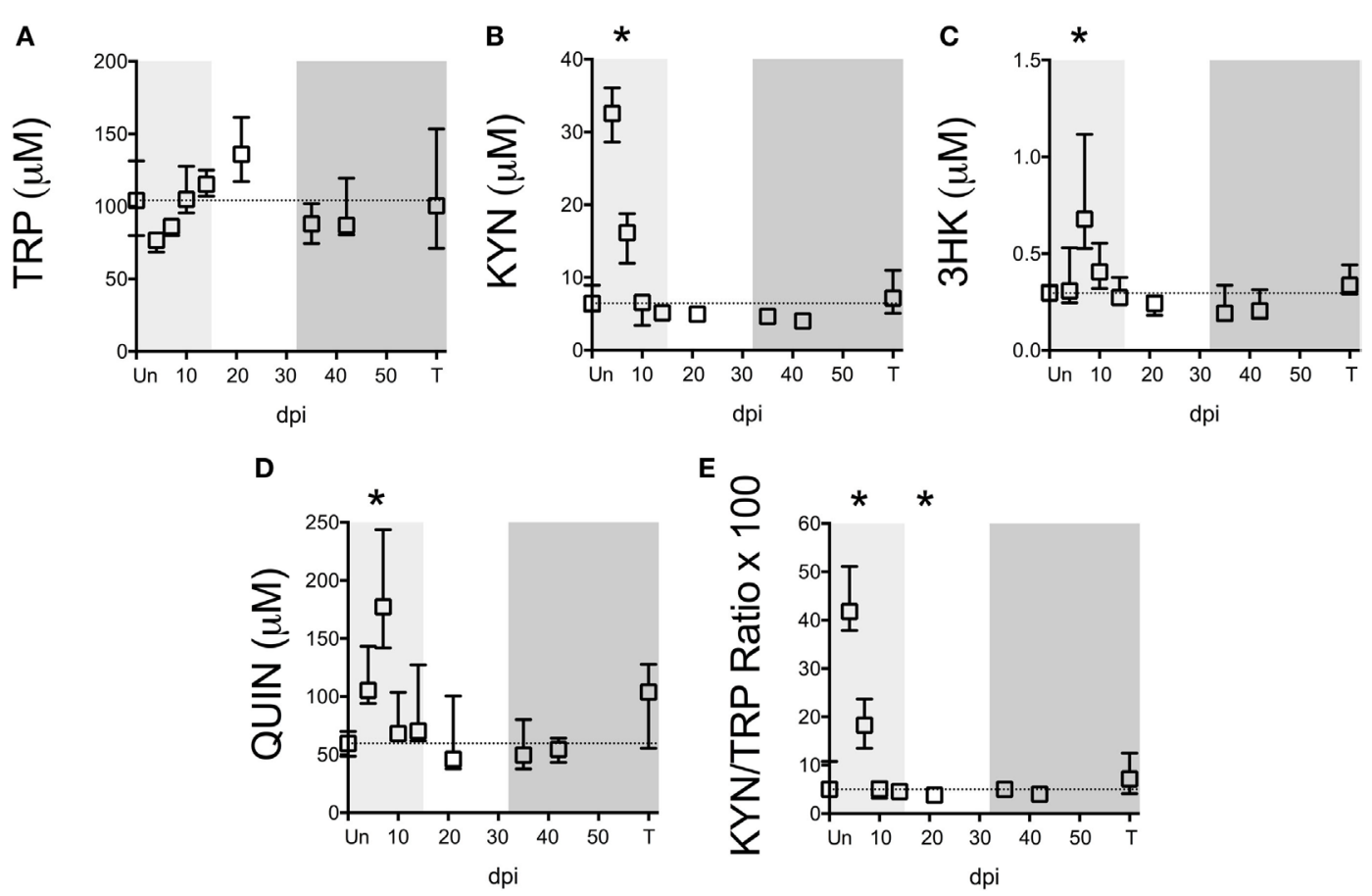

FIGURE 2 | Longitudinal analysis of kynurenine pathway (KP) metabolites in spleens from SIV-infected pigtailed macaques. Archived spleen samples from 58 animals euthanized at various points during infection (ranging from 5 to 9 animals per time point) were analyzed for levels of tryptophan (TRP) and KP metabolites: (A) TRP, (B) kynurenine (KYN), (C) 3-hydroxykynurenine (3HK), (D) quinolinic acid (QUIN), and (E) KYN/TRP ratio $\times 100$. Dotted lines represent the medians of uninfected controls for each metabolite. Light gray shading represents the acute phase of infection (0-14 dpi), and dark gray shading represents the chronic phase of infection ( $\geq 35 \mathrm{dpi}$ ) in our model. Asterisks ${ }^{*}$ ) indicate whether the peak during acute infection or the total values during asymptomatic or chronic infection was significantly different $(p<0.05)$ from uninfected controls by Mann-Whitney $U$ test followed by Bonferroni correction.

differences of the diverse tissue morbidities that occur during HIV/SIV infection. TRP was largely stable in the tissues (brain and spleen), even rising above uninfected levels at certain time points despite substantial reductions in the circulating fluids (CSF and plasma) (Figure 3A). In contrast, KYN, 3HK, QUIN, and KYN/TRP levels diverged according to peripheral vs. central lines, with the CNS displaying more robust fold changes than the periphery, particularly during chronic infection (Figures 3B-E). A noticeable second spike in each animal's plasma QUIN levels at day 14 of acute infection was likely a result of drainage of QUIN from the CSF to the plasma (Figure 3D), given that CSF was the only site that still had highly elevated levels at this time point, highlighting the diversity of tissue sites influencing plasma levels.

\section{Preservation of Intracellular TRP Levels in Macrophages}

Given the robust depletion of TRP in the circulating plasma and CSF and its relative stability in the spleen and brain tissues, we hypothesized that cells within tissues might preserve intracellular levels of TRP at the expense of circulating TRP. Macrophages and other cells types such as dendritic cells (DCs) are capable of suppressing $\mathrm{T}$ cell proliferation in vitro via IDO-mediated TRP catabolism $(37,38)$. We chose the macrophage as a representative immune cell type to further study in vitro due to its critical importance in both the brain and periphery during HIV/SIV infection: in the brain, macrophages, and the closely related microglia are considered to be the single-most important expressers of IDO1 and downstream KP enzymes due to their ability to produce copious amounts of the neurotoxin and KP metabolite quinolinic acid (39-42). Additionally, a dramatic influx of monocytic lineage cells into both the spleen and the brain has been established during both acute and chronic infection; these cells are thought to be a major driver of HIV/SIV-induced tissue pathology in both sites in conjunction with resident macrophages (43-46). Furthermore, macrophages are thought to be long-lived viral reservoirs in both the spleen and brain, as productively infected macrophages can be isolated from both tissue sites in SIV-infected macaques throughout infection (47). Thus, we stimulated monocytederived pigtailed macaque macrophages with IFN $\gamma$ to model the in vitro kinetics of KP induction. Supernatant TRP levels dropped immediately at $24 \mathrm{~h}$ and stayed below control levels (Figure 4A, $p=0.006)$. Corresponding to the drop in TRP in the supernatant, the upstream metabolites KYN and $3 \mathrm{HK}$ peaked at $24 \mathrm{~h}$, while the terminal pathway metabolite QUIN peaked at $48 \mathrm{~h}$ (Figure 4B). All three metabolites increased significantly above controls during the time course (Figure 4B, $p=0.037$ for KYN, $p=0.002$ for $3 \mathrm{HK}$, and $p=0.009$ for QUIN).

In contrast to the immediate and sustained drop in supernatant TRP levels, intracellular TRP suffered only slight losses that did not reach significance (Figure $4 \mathrm{C}, p=0.256$ ). Some animal donors even displayed slight increases in TRP, while losses in intracellular TRP only occurred in macrophages that 

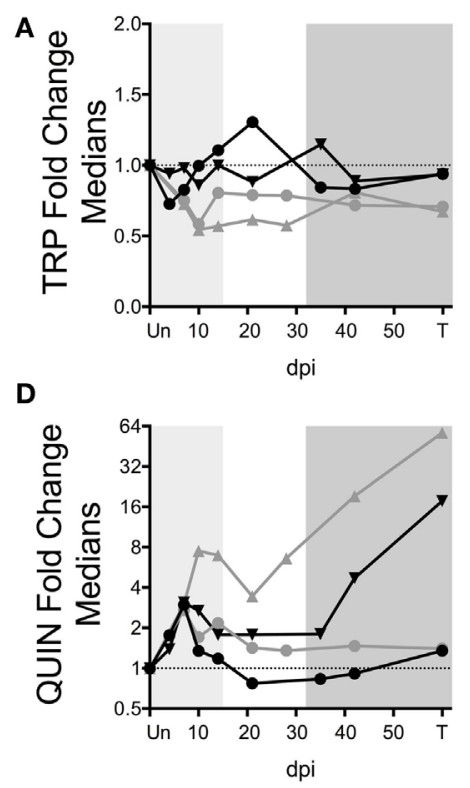

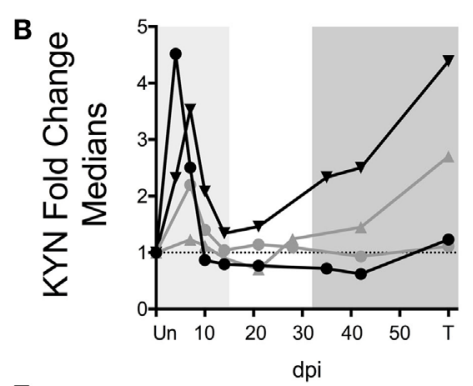

E

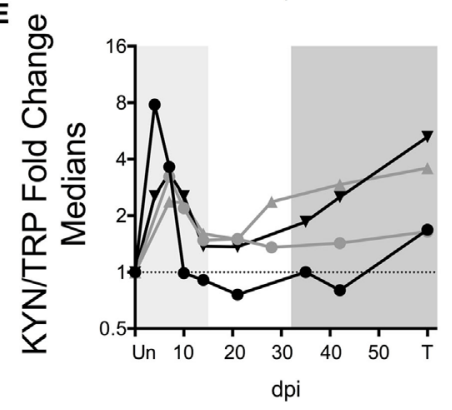

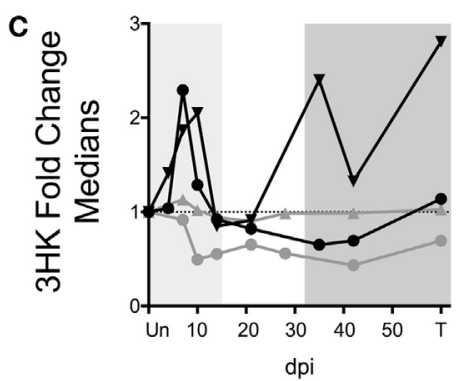

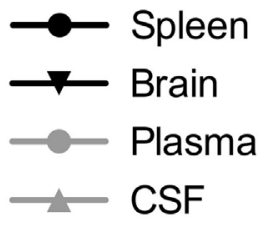

FIGURE 3 | Comparison of fold changes in kynurenine pathway metabolites in spleen, brain (striatum), plasma, and CSF from SIV-infected pigtailed macaques. The median fold changes for tryptophan (TRP) (A), kynurenine (KYN) (B), 3HK (C), QUIN (D), and KYN/TRP ratios (E) are overlaid for each respective tissue. The horizontal dotted line represents the median of uninfected animals. Light gray shading represents the acute phase of infection ( $0-14$ dpi), and dark gray shading represents the chronic phase of infection ( $\geq 35 \mathrm{dpi}$ ) in our model. Striatal brain and CSF metabolite data have been modified from a previously published version (32).

had depleted $>95 \%$ of TRP in the supernatant. The maintenance of intracellular TRP occurred despite modest increases in KYN, 3HK, and QUIN intracellularly (Figure 4D), although only QUIN reached significance $(p=0.002)$. Both supernatant and intracellular KYN/TRP ratios were significantly elevated (Figure $4 \mathrm{E}, p=0.017$ and $p=0.006$, respectively). In general, fold changes for all of the analytes were greater in the supernatant than in the lysates, suggesting that the cells actively secreted KP metabolites as they were being generated at each step in the pathway and replenished intracellular TRP levels at the expense of the extracellular milieu.

Finally, we determined the kinetics of IDO 1 in response to IFN $\gamma$ and IFN $\beta$, because chronic stimulation of type I IFN responses by virus is thought to contribute to chronic induction of IDO1 in $\mathrm{HIV} / \mathrm{SIV}$ infection in addition to IFN $\gamma(48)$. However, in vitro, IFN $\gamma$, but not IFN $\beta$, significantly induced IDO1 (Figure 4F, $p<0.0001$ for IFN $\gamma, p=0.772$ for IFN $\beta$ ).

\section{Kinetics of KP Enzymes during SIV Infection in Spleen}

In addition to the ability of cells to preserve intracellular levels of TRP, a deficiency in IDO1 expression could also explain the lack of TRP depletion in tissues. We thus analyzed the expression of IDO1 mRNA as well as other key enzymes in the KP in spleens of the SIV-infected macaques by NanoString. Paralleling trends in the CNS of these animals (32), we found that upstream enzymes (IDO1, KMO, and KYNU) displayed significant mRNA upregulation during at least one phase of infection (Figures 5A-C), while downstream enzymes (HAAO and $Q P R T$ ) were either downregulated or unchanged (Figures 5D,E). Importantly, IDOI was significantly elevated only during acute infection (Figure 5A, $p=0.012$ at day 4 p.i.), suggesting that while the lack of TRP depletion in the spleen during acute infection was due to tissue preservation of TRP, chronically it was due to a lack of local IDOI induction.

Despite the fact that SIV/HIV can induce IDO1 both directly and indirectly $(49,50)$, spleen SIV RNA peaked later than IDO1 (days 7 vs. 4 p.i.) during acute infection ( $p=0.012$ for SIV at day 7 p.i.), and remained elevated throughout asymptomatic $(p=0.012)$ and chronic infection $(p<0.001)$, suggesting that the lack of IDO1 induction chronically was not due to a lack of virus (Figure 5F). Finally, spleen IDO1 expression correlated strongly with spleen IDO1 activity (KYN/TRP ratios) (Figure 6A, $r=0.614, p<0.0001)$. Likewise, IDO1 mRNA in PBMCs positively correlated with KYN/TRP ratios in the plasma (Figure 6B, $p<0.0001, r=0.552$ ). These data confirmed the close relationship between local IDO1 mRNA levels and local IDO1 enzyme activity.

Notably, the lack of chronic IDO1 induction in the spleen was not due to a total of peripheral KP activation chronically in our model, as ileal and colonic gut tissue from subsequent animals demonstrated significant upregulation of IDO1 enzyme mRNA during chronic infection (Figure S4 in Supplementary Material; $p=0.024$ for ileum, $p=0.048$ for colon IDO1 expression terminally compared to uninfected). KMO and KYNU expression trended upwards during chronic infection in these gut tissues, while HAAO and QPRT trended downwards, similar to what 

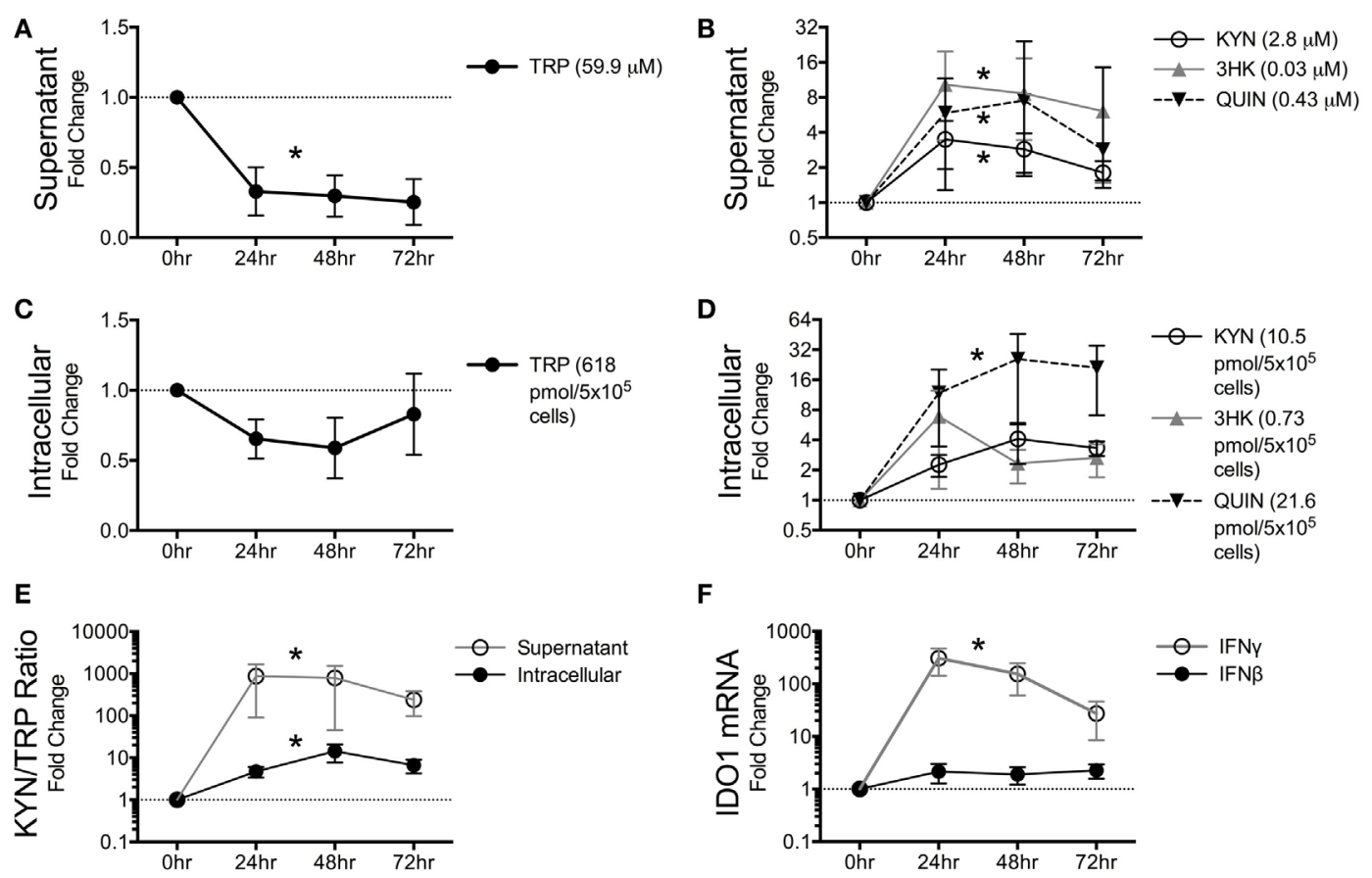

FIGURE 4 | Macaque macrophages maintain intracellular tryptophan (TRP) levels at the expense of extracellular TRP during kynurenine pathway activation. Pigtailed macaque macrophages were stimulated with $25 \mathrm{ng} / \mathrm{mL}$ IFN $\gamma$. After $0,24,48$, and $72 \mathrm{~h}$, cell-free supernatants were harvested, and cell cultures were halved into aliquots for measurements of mRNA (IDO1) and metabolites (TRP, KYN, 3HK, and QUIN). To control for minor well-to-well variations in cell number that could affect metabolic turnover, intracellular and extracellular metabolites were normalized to intracellular and extracellular levels of the amino acid tyrosine, respectively. Data are represented as means \pm SEM of the fold change over unstimulated controls at each time point. The average raw values of each metabolite in the unstimulated controls prior to fold change transformation are shown in parentheses on each graph (micromolar for supernatants; pmol/ $5 \times 10^{5}$ cells for intracellular lysates). The dotted lines represent the unstimulated controls at each time point. Results are from six independent experiments from different macaques, each with two cell culture technical replicates. (A) TRP levels in macrophage supernatants following IFN $\gamma$ stimulation. (B) KYN, 3HK, and QUIN levels in macrophage supernatants following IFN $\gamma$ stimulation. (C) Intracellular TRP from harvested cells following IFN $\gamma$ stimulation. (D) Intracellular metabolites KYN, 3HK, and QUIN from harvested cells following IFN $\gamma$ stimulation. (E) Intracellular and extracellular (supernatant) levels of KYN/TRP ratios, a surrogate for IDO1 enzyme activity, in macaque macrophages following IFN $\gamma$ stimulation. (F) Intracellular IDO1 mRNA expression levels normalized to GAPDH mRNA in macrophage Iysates following IFN $\gamma$ or IFN $\beta$ stimulation as compared to unstimulated cells. Asterisks $\left(^{*}\right)$ represent analytes that were statistically different as a whole across all time points compared to controls as analyzed by the Friedman test for non-parametric, repeated measures data.

was observed in the spleen tissue chronically, although none of these trends were statistically significant. The chronic induction of IDO1 that we observed in these gut tissues is consistent with induction observed by others in gut tissue of SIV-infected rhesus macaques and confirms the involvement of the gut in the pervasive immunosuppressive features of chronic SIV infection (3).

\section{Cell-Specific ID01 Expression in Chronically Infected Spleen}

We next examined whether the lack of IDO1 induction chronically in the spleen was due to dysfunction or possibly even depletion of antigen-presenting cells (APCs), which are typically the highest IDO1 expressers, although the cell-specific contributions during HIV/SIV infection are not well established. Splenic mononuclear cells (MNCs) were harvested immediately following euthanasia in a subsequent group of animals. These chronically infected animals were clearly immunocompromised, consistent with our model, as levels of CD4+ T cells in their peripheral blood were well below baseline during chronic infection (Figure 7A). Splenic MNCs from two of these infected animals underwent cell sorting by FACS (see Figure S1 in Supplementary Material for sample gating) and qRT-PCR for cell-specific IDO1 expression. From these FACS-sorted cells, we found that myeloid dendritic cells (mDCs) and CD14+ monocytes from the chronically infected spleens maintained their ability to express high levels of IDO1 mRNA (Figure 7B). Our finding that $\mathrm{mDC}$ expressed the highest levels of IDO1 is in agreement with a previous study in HIV-infected patients in which staining for IDO1 protein in lymph nodes mostly colocalized with an mDC-specific marker (2).

Given that the spleen APCs were capable of expressing IDO1, we next compared the proportions of various cell types to one another by flow cytometry to see whether a relative decline in APC number could explain the surprising lack of IDO1 expression in the chronically infected spleens (representative gating is shown in Figure S2 in Supplementary Material). The analysis revealed that $\mathrm{B}, \mathrm{NK}$, and $\mathrm{CD} 8+\mathrm{T}$ lymphocytes appeared to be present at higher proportions in the spleens of infected animals compared to uninfected animals (Figure 7C). However, due to losses in splenic CD4+ T cells during infection, the total lymphocyte percentage remained the same (Figure 7D, first panel). 

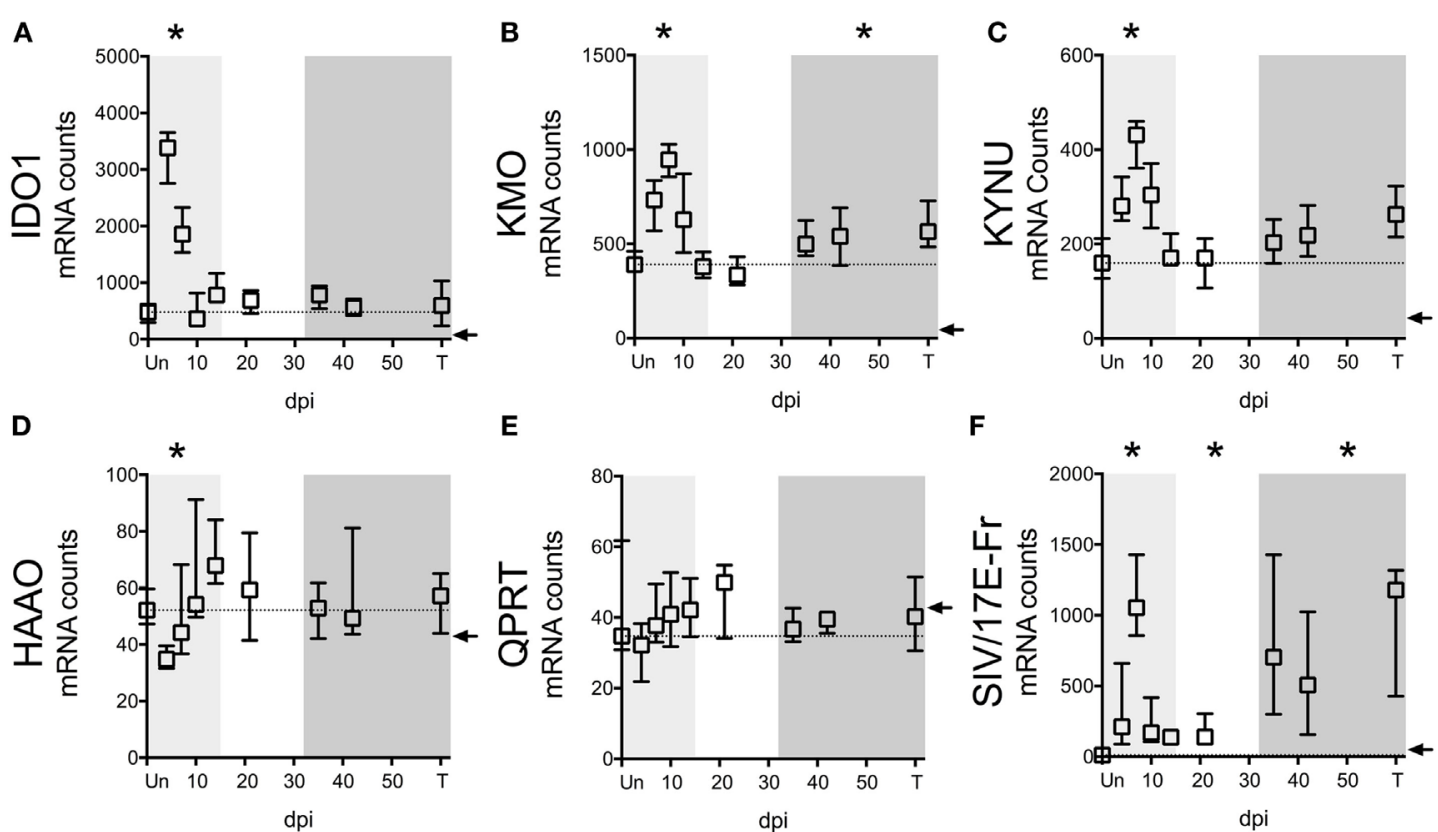

E

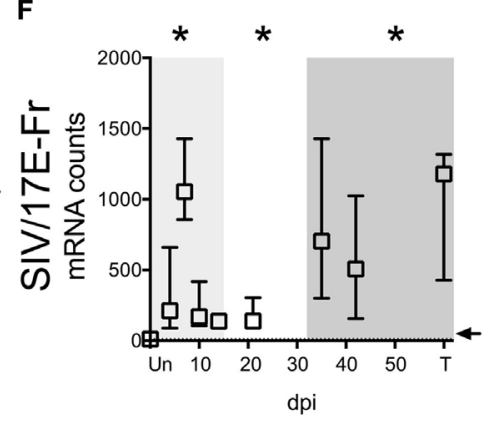

FIGURE 5 | IDO1 transcriptional regulation mirrors kynurenine (KYN)/tryptophan (TRP) induction in spleens of SIV-infected pigtailed macaques mRNA was harvested from spleens of 58 animals euthanized at various points following SIV infection and analyzed for transcriptional expression of SIV RNA and enzymes in the QUIN/NAD+ producing axis of the IDO1 pathway of TRP metabolism. (A) Expression of IDO1, which mediates the oxidative cleavage of the pyrrole ring of TRP to form L-formylkynurenine, the precursor to KYN. (B) Expression of kynurenine 3-monooxygenase (KMO), also known as kynurenine 3-hydroxylase, which adds a hydroxyl group to KYN to generate $3 \mathrm{HK}$. (C) Expression of kynureninase (KYNU), which catalyzes the hydrolytic cleavage of $3 \mathrm{HK}$ to form $3 \mathrm{HANA}$ and also catalyzes the cleavage of KYN to form anthranilic acid. (D) Expression of 3-hydroxyanthranilate-3,4-dioxygenase (HAAO; also known as 3HAO), which oxidatively cleaves the ring of 3HANA to form 2-amino-3-carboxymuconic semialdehyde, the precursor to QUIN. (E) Expression of quinolinate phosphoribosyltransferase (QPRT), which mediates the conversion of quinolinic acid into NAD+. (F) Expression of SIV/17E-Fr Gag RNA. The dotted lines in graphs (A-E) represent the medians of uninfected controls. Arrows represent the background threshold of the assay. Asterisks $\left({ }^{*}\right)$ represent time points that are significantly different $(p<0.05)$ from uninfected values by Kruskal-Wallis with Bonferroni correction.

As for APCs, we observed depletion of mDCs (Figure 7D, second panel; $p=0.024$ ) but an increase in monocytes (Figure 7D, third panel; $p=0.024)$. Thus, the IDO1 deficiency in the spleen was not due to a complete lack of IDO1 expression from APCs nor did it appear to be due to a total loss of IDO1-expressing APCs within the MNC population, although both factors may still contribute to this phenomenon.

\section{DISCUSSION}

Overall, our comprehensive analysis of the KP in various anatomical sites in SIV-infected macaques reveals tremendous insight into the tissue-specific regulation of KP enzymes and metabolites. Despite our hypothesis that inflammation would trigger ubiquitous changes in the KP, the tissues and circulating fluids displayed highly variable patterns in metabolites and enzymes. Most importantly, we did not find any significant reductions in TRP in either the spleen or brain at any time point during infection, despite TRP levels in the plasma and CSF being reduced by up to $50 \%$, on par with changes reported in plasma and CSF of HIV-infected patients $(14,51,52)$. Our in vivo findings were further supported by in vitro experiments in which macrophages stimulated with IFN $\gamma$ maintained intracellular TRP levels by depleting extracellular TRP.
These data substantiate a growing body of mechanisms by which cells and tissues may subvert TRP losses during KP activation. For example, IFN $\gamma$, which is the major inducer of IDO1, also upregulates tryptophanyl-tRNA synthetase (TTS), an enzyme that complexes intracellular TRP with its corresponding TRP-tRNA $(53,54)$. Thus, cells exposed to IFN $\gamma$ may maintain or even accumulate intracellular levels of TRP-tRNA complexes during KP activation, protecting them from anergy that occurs when uncharged tRNAs trigger induction of the GCN2 stress kinase pathway $(9,52,55)$. Furthermore, given that extracellular levels of TRP must be below $3 \mu \mathrm{M}$ in vitro in order to activate the GCN2 stress pathway in T cells (9), and the fact that we detected levels of TRP in the tissues well above this concentration throughout infection ( $100 \mu \mathrm{M}$ for spleen, $20 \mu \mathrm{M}$ for brain), it seems unlikely that TRP depletion is a major contributor to T cell dysfunction during HIV/SIV infection. These findings question some of the fundamental assumptions regarding the role of TRP metabolism during immunosuppression and suggest that future studies focus more on the KP metabolites themselves.

However, it is important to distinguish between free TRP and total TRP, as $>90 \%$ of the circulating TRP is bound to albumin in the blood, and only the free TRP is thought to be accessible to cells. Our TRP measurements in this study represent total TRP (i.e., albumin-bound + free TRP). Thus, a 10\% change in total 

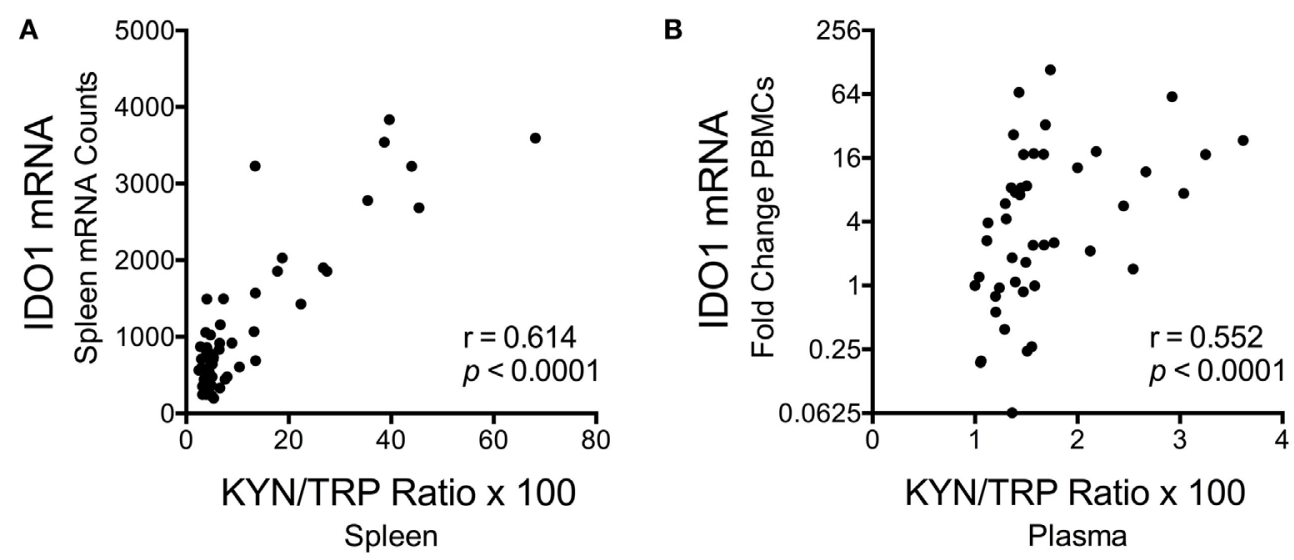

FIGURE 6 | Correlations between longitudinal kynurenine (KYN)/tryptophan (TRP) ratios and IDO1 mRNA expression in spleen and blood of SIV-infected pigtailed macaques. (A) Spearman's rank correlation of splenic IDO1 mRNA expression and splenic KYN/TRP ratios harvested from animals euthanized at various points postinfection ( $n \geq 5$ animals per timepoint). (B) Spearman's rank correlation of peripheral blood mononuclear cell IDO1 mRNA expression and plasma KYN/TRP ratios from five animals followed longitudinally (3 preinfection blood draws averaged together, as well as 7 postinfection blood draws at days $7,10,14,21,28,42$, and approximately 84 dpi, are depicted).

TRP could deplete all available free TRP. However, multiple studies have shown that HIV infection is associated with a decrease in serum albumin as well (29-31). We similarly found evidence for serum albumin depletion in our model, and furthermore, found that it paralleled the trends in plasma TRP depletion. These data suggest that changes in free TRP in the plasma may actually be more stable than previously thought, despite the overall losses in total plasma TRP. However, it is still conceivable that in a tissue microenvironment, such as a germinal center, levels of TRP may reach dangerously low nadirs, or that chronic exposure to slightly lower-than-normal levels of TRP may have long-term consequences on $\mathrm{T}$ cell function that has not yet been discerned. Additionally, perfusion of tissues used in this study may have masked any potential changes in TRP levels in extracellular spaces. Future studies that shed light on the differences between extracellular and intracellular TRP and their respective impacts on immune dysfunction are warranted.

In addition to KP metabolites, our results also shed light on the transcriptional regulation of KP enzymes during infection. Concordant with our previous data in brain tissue (32), we found that upstream enzymes in the KP (IDO1, KMO, and $K Y N U$ ) displayed more upregulation during acute infection than downstream enzymes (HAAO and QPRT). Intriguingly, we also found that IDO1 expression in the spleen actually peaked prior to peak spleen viral loads (days 4 vs. 7 p.i.) during acute infection. This peak in IDO1 at day 4 p.i. coincided with the robust peak in $I F N \beta$ and multiple IFN-stimulated genes $(M x A, I R F 7)$ recently published in our model (43). In that study, IFN $\alpha$ expression also peaked at day 4 p.i. but was less robustly induced, while $I F N \gamma$ and other known inducers of IDO such as IL6 and TNF $\alpha$ displayed a delayed induction as late as days 7 or 14 p.i. (43), suggesting that the complex milieu of factors that can stimulate IDO1 expression are not synchronized during infection. Others have shown similar findings during acute infection in plasma of SIV-infected macaques, where IDO1 activity (KYN/TRP ratios) peaked before viral loads during acute infection and coincided with an acute spike in type I IFN levels (56). However, type I IFN is not as proficient as type II IFN at inducing IDO1 in vitro (57), which we confirmed in our macrophage experiments. Rather than type I IFN being responsible for the induction of IDO1 during acute infection, it is possible that this earlier peak in IDO1 before virus instead reflects rapid downregulation of IDO1 by the same mechanisms involved in the contraction of acute type I IFN responses.

A similar mechanism may be at work during chronic infection, when IDO1 expression appeared to be suppressed despite high levels of spleen viral loads, induction of other KP enzymes (e.g., KMO), and presence of $\mathrm{mDCs}$ and CD14+ cells capable of expressing IDO1. One such potential negative regulator of IDO1 is the suppressor of cytokine signaling (SOCS) family of proteins. SOCS3 in particular has been shown to inhibit Jak/Stat signaling, which is required for IDO1 expression, and can also directly target IDO1 protein for proteasomal degradation (58). Notably, SOCS3 has been shown to be elevated in tonsillar tissue of HIV-infected patients (59) and in the CNS (60) and spleens of our SIV-infected macaques (43). In the SIV-infected spleens, SOCS3 expression was shown to be highly expressed not only during acute infection but also throughout asymptomatic and chronic infection, demonstrating a strong potential reason for the suppression of IDO1 despite abundant virus stimuli during chronic infection (43).

Alternatively, expression of IDO1 in at least one DC cell type (CD19+ DCs) has been shown to be dependent on CD4+ T cells in a murine leukemia virus model of retroviral infection (61). Thus, the progressive loss and/or exhaustion of CD4+ T cells in the periphery during chronic SIV infection in our model could contribute to a reduced production of IDO1 by CD4+ $\mathrm{T}$ celldependent DCs (43). However, it is important to note that IDOI was significantly upregulated chronically in the colon and ileum, where CD4+ T cell depletion is also known to occur (62). This discrepancy in IDO1 induction may be a result of differences in the cell types and/or cytokines contributing to IDO1 levels in 

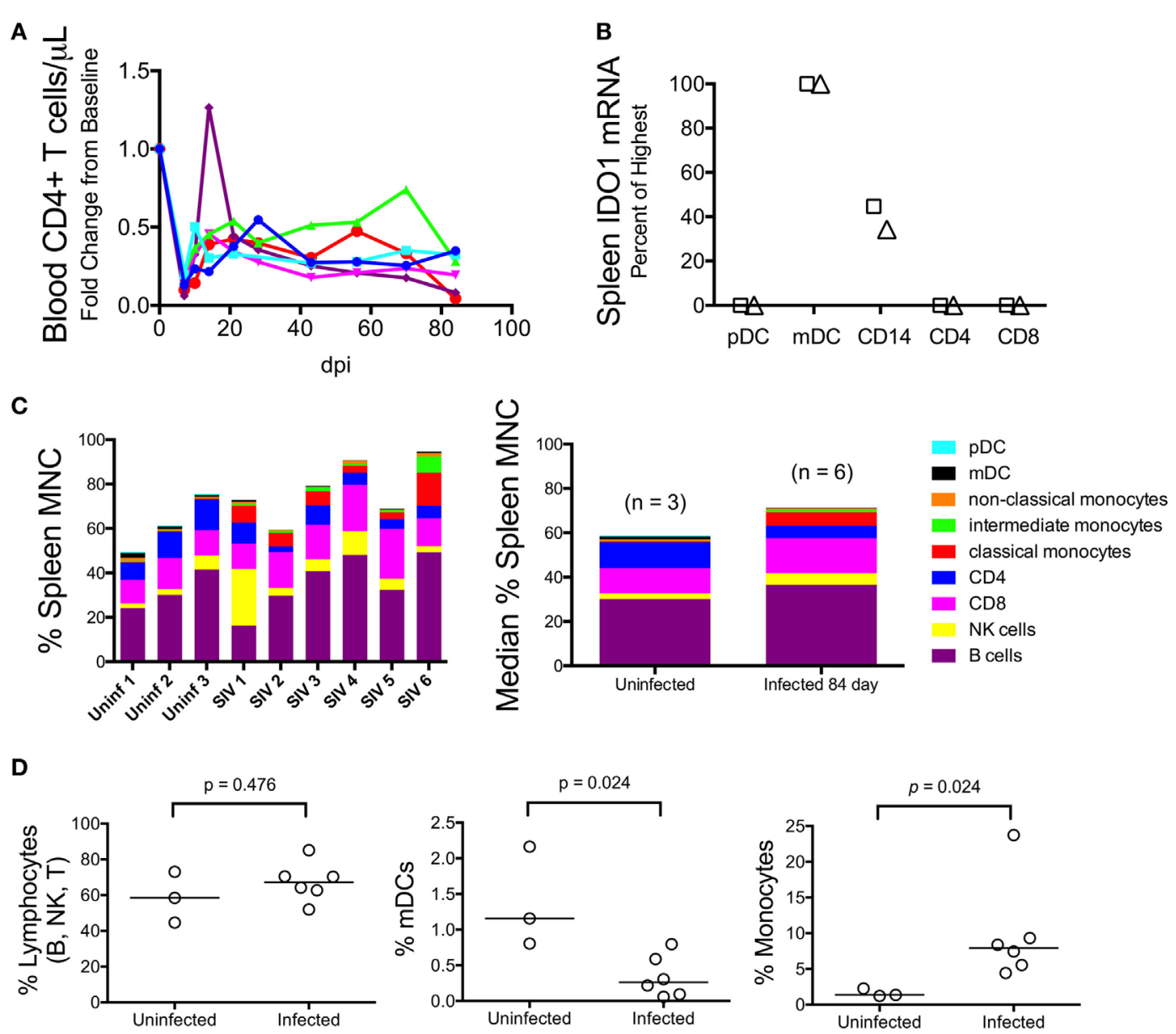

FIGURE 7 | Myeloid dendritic cells (mDCs) express the highest levels of IDO1 mRNA in chronically SIV-infected macaque spleen. (A) Absolute CD4+ T cell counts in the blood were measured longitudinally using complete blood count and flow cytometry in five animals to confirm immune suppression. (B) Cells were teased out of spleen tissue from two animals (designated as the triangle and square, respectively) at 84 days p.i., then sorted by fluorescence-activated cell sorting to separate pure populations of pDCs, mDCs, CD14+ monocyte/macrophages, CD4+ T cells, and CD8+ T cells. mRNA was extracted from the isolated cells and analyzed for IDO1 expression levels. All data were normalized to internal GAPDH housekeeping mRNA and then to the highest expressing cell type, which was the $\mathrm{mDC}$ population in both samples, by the $2^{-\Delta \Delta C t}$ method. Fold change data were transformed to a percentage of the mDC values. Similar results were obtained with normalization to $18 \mathrm{~S}$ ribosomal RNA. (C) Mononuclear cells from all five chronically infected animals as well as three uninfected controls were analyzed by an extensive flow cytometry panel for various cell markers. Raw cell percentages are depicted in the left-most panel; median cell percentages are shown in the panel on the right. (D) Specific populations of cells were further analyzed by Mann-Whitney test to determine statistical significance.

different tissue sites. For example, macrophages and microglia are thought to be the major producers of IDO1 in the brain (41), whereas mDCs may express the highest level of IDO1 in the spleen (data shown here) and lymph nodes (2) during HIV/ SIV infection. Conversely, IFN $\alpha$ subtypes are known to differ in different tissue sites; such differences could modulate the induction of IDO1 or IDO1 modulators (63). Future studies will be necessary in order to examine the cell-specific requirements of IDO and other KP enzyme induction in other peripheral tissue sites and during acute vs. chronic infection.

Finally, the results of our study have implications for the treatment of not only HIV but also other diseases in which IDO1 and the KP are thought to play a role, such as cancer (64). While our results suggest that circulating TRP levels clearly overestimate the extent of TRP depletion in the tissues, the KYN/TRP ratio in the plasma and the QUIN/TRP ratio in the CSF (32) are consequently highly sensitive biomarkers of inflammation and may help to identify patients in need of immunotherapy prior to irreparable tissue damage. Importantly, cART does not fully restore peripheral KP metabolites to uninfected levels even in patients with undectable viremia $(1,65,66)$. IDO1 therefore represents a potentially important therapeutic target that could be used in conjunction with cART in HIV-infected patients or in conjunction with chemotherapy in cancer patients (64). However, mixed results have been observed following attempts to inhibit IDO1 with compounds such as the TRP analog, 1-methyl-D-tryptophan (D-1MT). For example, administration of D-1MT in conjunction with ART during SIV infection of rhesus macaques resulted in only a transient improvement in plasma TRP levels but no change in plasma KYN levels (67). Our data suggest that reducing the 
KP metabolite levels is of greater importance than restoring TRP, as TRP levels are not at a limiting concentration in the tissues at any time point during infection. Boosting immunotherapy in the rhesus macaque model by combining D-1MT with anti-CTLA- 4 antibodies and vaccination resulted in severe side effects including acute pancreatitis (68). Additionally, the beneficial effects of D-1MT may be due to side effects independent of IDO1 (69). These non-specific effects and the relatively high micromolar concentrations of D-1MT required for an effect render D-1MT an unlikely candidate for further applications in patients. As a result, second generation inhibitors of IDO1 continue to be developed (64). However, inhibition of IDO1 is likely complex due to the potential rebound effect of newly uninhibited $\mathrm{T}$ cells producing IFN $\gamma$ - a sign that the IDO1 inhibitor is working - that in turn could paradoxically induce IDO1 (67). Nevertheless, several IDO1 inhibitors including indoximod and epacadostat are now undergoing Phase I/II clinical trials in cancer patients in whom induction of IDO and resulting evasion of anti-tumoral immune responses may play a role (70-72). Advances made toward immunotherapy in HIV-infected patients may also benefit cancer patients and vice versa.

In conclusion, our study suggests that cellular TRP depletion is likely not a major component of IDO1's immunosuppressive capabilities during HIV/SIV infection. In fact, myriad mechanisms exist to stave off TRP starvation, including (1) downregulation of IDO1 expression by SOCS3; (2) upregulation of TTS to allow cells to store TRP complexed to the TRP-tRNA during IFN $\gamma$ stimulation; (3) reductions in serum albumin during infection, which alleviates deficits in free TRP; and (4) the relatively high levels of TRP in the tissues, making the likelihood that TRP would be depleted below the necessary $<3 \mu \mathrm{M}$ relatively unlikely. Clearly, these findings will need to be confirmed in other models, but nevertheless they shed light on how cells and tissues prioritize TRP use in the face of KP activation.

\section{ETHICS STATEMENT}

All animal studies were approved by the Johns Hopkins Animal Care and Use Committee; all animals were humanely

\section{REFERENCES}

1. Jenabian MA, Patel M, Kema I, Kanagaratham C, Radzioch D, Thebault P, et al. Distinct tryptophan catabolism and Th17/Treg balance in HIV progressors and elite controllers. PLoS One (2013) 8:e78146. doi:10.1371/journal. pone.0078146

2. Favre D, Mold J, Hunt PW, Kanwar B, Loke P, Seu L, et al. Tryptophan catabolism by indoleamine 2,3-dioxygenase 1 alters the balance of TH17 to regulatory T cells in HIV disease. Sci Transl Med (2010) 2:32ra36. doi:10.1126/ scitranslmed.3000632

3. Boasso A, Vaccari M, Hryniewicz A, Fuchs D, Nacsa J, Cecchinato V, et al. Regulatory T-cell markers, indoleamine 2,3-dioxygenase, and virus levels in spleen and gut during progressive simian immunodeficiency virus infection. J Virol (2007) 81:11593-603. doi:10.1128/JVI.00760-07

4. Boasso A, Hardy AW, Anderson SA, Dolan MJ, Shearer GM. HIV-induced type I interferon and tryptophan catabolism drive T cell dysfunction despite phenotypic activation. PLoS One (2008) 3:e2961. doi:10.1371/journal.pone.0002961

5. Gaardbo JC, Troseid M, Stiksrud B, Midttun O, Ueland PM, Ullum H, et al. Increased tryptophan catabolism is associated with increased frequency of treated in accordance with federal guidelines and institutional policies.

\section{AUTHOR CONTRIBUTIONS}

JD, JC, ES, EE, MZ, and DG designed the experiments. JD, JC, ES, and EE performed the experiments. JD, JC, and ES analyzed the experiments. JD wrote the manuscript with significant input from JC, ES, EE, MZ, and DG.

\section{ACKNOWLEDGMENTS}

The authors would like to acknowledge Suzanne Queen and Brandon Bullock for their assistance in the macaque studies. The authors would also like to thank the SKCCC Flow Cytometry Core at Johns Hopkins for assistance in the sorting of spleen cells. The authors would like to acknowledge that the Agilent GCMS is a shared resource between the laboratories of Dr. David Graham at the Johns Hopkins University School of Medicine and Dr. Robert Schwarcz at the University of Maryland School of Medicine Maryland Psychiatric Research Center. The authors would like to thank Dr. Francesca Notarangelo for her valuable assistance with the GCMS instrument, and both Dr. Schwarcz and Dr. Notarangelo for invaluable discussions on the kynurenine pathway, particularly as it relates to neurological disorders.

\section{FUNDING}

This work was supported by the following National Institutes of Health grants: R01 MH085554, R01 MH087233, and P01 MH070306, as well as the National Center for Research Resources and the Office of Research Infrastructure Programs (ORIP) of the National Institutes of Health through Grant Number OD013117.

\section{SUPPLEMENTARY MATERIAL}

The Supplementary Material for this article can be found online at http://journal.frontiersin.org/article/10.3389/fimmu.2016. 00605/full\#supplementary-material.
CD161+Tc17/MAIT cells, and lower CD4+ T cell count in HIV-1 infected patients on cART after two years of follow-up. J Acquir Immune Defic Syndr (2015) 70:228-35. doi:10.1097/QAI.0000000000000758

6. Bipath P, Levay PF, Viljoen M. The kynurenine pathway activities in a subSaharan HIV/AIDS population. BMC Infect Dis (2015) 15:346. doi:10.1186/ s12879-015-1087-5

7. Fuchs D, Moller AA, Reibnegger G, Werner ER, Werner-Felmayer G, Dierich MP, et al. Increased endogenous interferon-gamma and neopterin correlate with increased degradation of tryptophan in human immunodeficiency virus type 1 infection. Immunol Lett (1991) 28:207-11. doi:10.1016/0165-2478(91)90005-U

8. Werner ER, Fuchs D, Hausen A, Jaeger H, Reibnegger G, Werner-Felmayer $\mathrm{G}$, et al. Tryptophan degradation in patients infected by human immunodeficiency virus. Biol Chem Hoppe Seyler (1988) 369:337-40. doi:10.1515/ bchm3.1988.369.1.337

9. Munn DH, Sharma MD, Baban B, Harding HP, Zhang Y, Ron D, et al. GCN2 kinase in T cells mediates proliferative arrest and anergy induction in response to indoleamine 2,3-dioxygenase. Immunity (2005) 22:633-42. doi:10.1016/ j.immuni.2005.03.013 
10. Frumento G, Rotondo R, Tonetti M, Damonte G, Benatti U, Ferrara GB. Tryptophan-derived catabolites are responsible for inhibition of $\mathrm{T}$ and natural killer cell proliferation induced by indoleamine 2,3-dioxygenase. J Exp Med (2002) 196:459-68. doi:10.1084/jem.20020121

11. Mezrich JD, Fechner JH, Zhang X, Johnson BP, Burlingham WJ, Bradfield CA. An interaction between kynurenine and the aryl hydrocarbon receptor can generate regulatory T cells. J Immunol (2010) 185:3190-8. doi:10.4049/ jimmunol.0903670

12. Lee SM, Lee YS, Choi JH, Park SG, Choi IW, Joo YD, et al. Tryptophan metabolite 3-hydroxyanthranilic acid selectively induces activated $\mathrm{T}$ cell death via intracellular GSH depletion. Immunol Lett (2010) 132:53-60. doi:10.1016/ j.imlet.2010.05.008

13. Hiramatsu R, Hara T, Akimoto H, Takikawa O, Kawabe T, Isobe K, et al. Cinnabarinic acid generated from 3 -hydroxyanthranilic acid strongly induces apoptosis in thymocytes through the generation of reactive oxygen species and the induction of caspase. J Cell Biochem (2008) 103:42-53. doi:10.1002/ jcb. 21384

14. Larsson M, Hagberg L, Norkrans G, Forsman A. Indole amine deficiency in blood and cerebrospinal fluid from patients with human immunodeficiency virus infection. J Neurosci Res (1989) 23:441-6. doi:10.1002/jnr.490230410

15. Clements JE, Mankowski JL, Gama L, Zink MC. The accelerated simian immunodeficiency virus macaque model of human immunodeficiency virus-associated neurological disease: from mechanism to treatment. J Neurovirol (2008) 14:309-17. doi:10.1080/13550280802132832

16. Zink MC, Suryanarayana K, Mankowski JL, Shen A, Piatak M Jr, Spelman JP, et al. High viral load in the cerebrospinal fluid and brain correlates with severity of simian immunodeficiency virus encephalitis. J Virol (1999) 73:10480-8.

17. Weed MR, Hienz RD, Brady JV, Adams RJ, Mankowski JL, Clements JE, et al. Central nervous system correlates of behavioral deficits following simian immunodeficiency virus infection. J Neurovirol (2003) 9:452-64. doi:10.1080/13550280390218751

18. Eriksson T, Lidberg L. Decreased plasma ratio of tryptophan to competing large neutral amino acids in human immunodeficiency virus type 1 infected subjects: possible implications for development of neuro-psychiatric disorders. J Neural Transm (1996) 103:157-64. doi:10.1007/BF01292624

19. Notarangelo FM, Wu HQ, Macherone A, Graham DR, Schwarcz R. Gas chromatography/tandem mass spectrometry detection of extracellular kynurenine and related metabolites in normal and lesioned rat brain. Anal Biochem (2012) 421:573-81. doi:10.1016/j.ab.2011.12.032

20. Eckstein JA, Ammerman GM, Reveles JM, Ackermann BL. Simultaneous profiling of multiple neurochemical pathways from a single cerebrospinal fluid sample using GC/MS/MS with electron capture detection. J Mass Spectrom (2008) 43:782-90. doi:10.1002/jms.1376

21. Drewes JL, Szeto GL, Engle EL, Liao Z, Shearer GM, Zink MC, et al. Attenuation of pathogenic immune responses during infection with human and simian immunodeficiency virus (HIV/SIV) by the tetracycline derivative minocycline. PLoS One (2014) 9:e94375. doi:10.1371/journal.pone.0094375

22. Lee PD, Sladek R, Greenwood CM, Hudson TJ. Control genes and variability: absence of ubiquitous reference transcripts in diverse mammalian expression studies. Genome Res (2002) 12:292-7. doi:10.1101/gr.217802

23. Chege D, Chai Y, Huibner S, McKinnon L, Wachihi C, Kimani M, et al. Evaluation of a quantitative real-time PCR assay to measure HIV-specific mucosal CD8+ T cell responses in the cervix. PLoS One (2010) 5:e13077. doi:10.1371/journal.pone.0013077

24. Harman AN, Wilkinson J, Bye CR, Bosnjak L, Stern JL, Nicholle M, et al. HIV induces maturation of monocyte-derived dendritic cells and Langerhans cells. J Immunol (2006) 177:7103-13. doi:10.4049/jimmunol.177.10.7103

25. Radonic A, Thulke S, Mackay IM, Landt O, Siegert W, Nitsche A. Guideline to reference gene selection for quantitative real-time PCR. Biochem Biophys Res Commun (2004) 313:856-62. doi:10.1016/j.bbrc.2003.11.177

26. Vandesompele J, De Preter K, Pattyn F, Poppe B, Van Roy N, De Paepe A, et al. Accurate normalization of real-time quantitative RT-PCR data by geometric averaging of multiple internal control genes. Genome Biol (2002) 3:RESEARCH0034. doi:10.1186/gb-2002-3-7-research0034

27. Gubern C, Hurtado O, Rodriguez R, Morales JR, Romera VG, Moro MA, et al. Validation of housekeeping genes for quantitative real-time PCR in in-vivo and in-vitro models of cerebral ischaemia. BMC Mol Biol (2009) 10:57. doi:10.1186/1471-2199-10-57
28. Meulendyke KA, Ubaida-Mohien C, Drewes JL, Liao Z, Gama L, Witwer KW, et al. Elevated brain monoamine oxidase activity in SIV- and HIV-associated neurological disease. J Infect Dis (2014) 210:904-12. doi:10.1093/infdis/jiu194

29. Mehta SH, Astemborski J, Sterling TR, Thomas DL, Vlahov D. Serum albumin as a prognostic indicator for HIV disease progression. AIDS Res Hum Retroviruses (2006) 22:14-21. doi:10.1089/aid.2006.22.14

30. Olawumi HO, Olatunji PO. The value of serum albumin in pretreatment assessment and monitoring of therapy in HIV/AIDS patients. HIV Med (2006) 7:351-5. doi:10.1111/j.1468-1293.2006.00391.x

31. Graham SM, Baeten JM, Richardson BA, Wener MH, Lavreys L, Mandaliya $\mathrm{K}$, et al. A decrease in albumin in early HIV type 1 infection predicts subsequent disease progression. AIDS Res Hum Retroviruses (2007) 23:1197-200. doi:10.1089/aid.2007.0065

32. Drewes JL, Meulendyke KA, Liao Z, Witwer KW, Gama L, Ubaida-Mohien C, et al. Quinolinic acid/tryptophan ratios predict neurological disease in SIVinfected macaques and remain elevated in the brain under cART. J Neurovirol (2015) 21:449-63. doi:10.1007/s13365-015-0334-2

33. McArthur JC, Brew BJ, Nath A. Neurological complications of HIV infection. Lancet Neurol (2005) 4:543-55. doi:10.1016/S1474-4422(05)70165-4

34. Schwarcz R, Kohler C. Differential vulnerability of central neurons of the rat to quinolinic acid. Neurosci Lett (1983) 38:85-90. doi:10.1016/0304-3940(83)90115-5

35. Okuda S, Nishiyama N, Saito H, Katsuki H. 3-Hydroxykynurenine, an endogenous oxidative stress generator, causes neuronal cell death with apoptotic features and region selectivity. J Neurochem (1998) 70:299-307. doi:10.1046/j.1471-4159.1998.70010299.x

36. Kumar AM, Borodowsky I, Fernandez B, Gonzalez L, Kumar M. Human immunodeficiency virus type 1 RNA Levels in different regions of human brain: quantification using real-time reverse transcriptase-polymerase chain reaction. J Neurovirol (2007) 13:210-24. doi:10.1080/13550280701327038

37. Munn DH, Shafizadeh E, Attwood JT, Bondarev I, Pashine A, Mellor AL. Inhibition of T cell proliferation by macrophage tryptophan catabolism. J Exp Med (1999) 189:1363-72. doi:10.1084/jem.189.9.1363

38. Hwu P, Du MX, Lapointe R, Do M, Taylor MW, Young HA. Indoleamine 2,3-dioxygenase production by human dendritic cells results in the inhibition of T cell proliferation. J Immunol (2000) 164:3596-9. doi:10.4049/ jimmunol.164.7.3596

39. Guillemin GJ, Smith DG, Smythe GA, Armati PJ, Brew BJ. Expression of the kynurenine pathway enzymes in human microglia and macrophages. Adv Exp Med Biol (2003) 527:105-12. doi:10.1007/978-1-4615-0135-0_12

40. Guillemin GJ, Smythe G, Takikawa O, Brew BJ. Expression of indoleamine 2,3-dioxygenase and production of quinolinic acid by human microglia, astrocytes, and neurons. Glia (2005) 49:15-23. doi:10.1002/glia.20090

41. Burudi EM, Marcondes MC, Watry DD, Zandonatti M, Taffe MA, Fox HS. Regulation of indoleamine 2,3-dioxygenase expression in simian immunodeficiency virus-infected monkey brains. J Virol (2002) 76:12233-41. doi:10.1128/JVI.76.23.12233-12241.2002

42. Alberati-Giani D, Ricciardi-Castagnoli P, Kohler C, Cesura AM. Regulation of the kynurenine metabolic pathway by interferon-gamma in murine cloned macrophages and microglial cells. J Neurochem (1996) 66:996-1004. doi:10.1046/j.1471-4159.1996.66030996.x

43. Williams DW, Engle EL, Shirk EN, Queen SE, Gama L, Mankowski JL, et al. Splenic damage during SIV Infection: role of T-cell depletion and macrophage polarization and infection. Am J Pathol (2016) 186:2068-87. doi:10.1016/ j.ajpath.2016.03.019

44. Fischer-Smith T, Bell C, Croul S, Lewis M, Rappaport J. Monocyte/macrophage trafficking in acquired immunodeficiency syndrome encephalitis: lessons from human and nonhuman primate studies. J Neurovirol (2008) 14:318-26. doi:10.1080/13550280802132857

45. Meltzer MS, Skillman DR, Gomatos PJ, Kalter DC, Gendelman HE. Role of mononuclear phagocytes in the pathogenesis of human immunodeficiency virus infection. Annu Rev Immunol (1990) 8:169-94. doi:10.1146/annurev. iy.08.040190.001125

46. Fischer T, Wyatt CM, D'Agati VD, Croul S, McCourt L, Morgello S, et al. Mononuclear phagocyte accumulation in visceral tissue in HIV encephalitis: evidence for increased monocyte/macrophage trafficking and altered differentiation. Curr HIV Res (2014) 12:201-12. doi:10.2174/ $1570162 X 12666140713165141$ 
47. Avalos CR, Price SL, Forsyth ER, Pin JN, Shirk EN, Bullock BT, et al. Quantitation of productively infected monocytes and macrophages of simian immunodeficiency virus-infected macaques. J Virol (2016) 90:5643-56. doi:10.1128/JVI.00290-16

48. Boasso A, Shearer GM. Chronic innate immune activation as a cause of HIV-1 immunopathogenesis. Clin Immunol (2008) 126:235-42. doi:10.1016/ j.clim.2007.08.015

49. Boasso A, Herbeuval JP, Hardy AW, Anderson SA, Dolan MJ, Fuchs D, et al. HIV inhibits CD4+ T-cell proliferation by inducing indoleamine 2,3-dioxygenase in plasmacytoid dendritic cells. Blood (2007) 109:3351-9. doi:10.1182/ blood-2006-07-034785

50. Mellor AL, Baban B, Chandler PR, Manlapat A, Kahler DJ, Munn DH. Cutting edge: $\mathrm{CpG}$ oligonucleotides induce splenic CD19+ dendritic cells to acquire potent indoleamine 2,3-dioxygenase-dependent $\mathrm{T}$ cell regulatory functions via IFN Type 1 signaling. J Immunol (2005) 175:5601-5. doi:10.4049/ jimmunol.175.9.5601

51. Huengsberg M, Winer JB, Gompels M, Round R, Ross J, Shahmanesh M. Serum kynurenine-to-tryptophan ratio increases with progressive disease in HIV-infected patients. Clin Chem (1998) 44:858-62.

52. Murray MF. Tryptophan depletion and HIV infection: a metabolic link to pathogenesis. Lancet Infect Dis (2003) 3:644-52. doi:10.1016/ S1473-3099(03)00773-4

53. Fleckner J, Martensen PM, Tolstrup AB, Kjeldgaard NO, Justesen J. Differential regulation of the human, interferon inducible tryptophanyl-tRNA synthetase by various cytokines in cell lines. Cytokine (1995) 7:70-7. doi:10.1006/ cyto.1995.1009

54. Fleckner J, Rasmussen HH, Justesen J. Human interferon gamma potently induces the synthesis of a $55-\mathrm{kDa}$ protein (gamma 2) highly homologous to rabbit peptide chain release factor and bovine tryptophanyl-tRNA synthetase. Proc Natl Acad Sci U S A (1991) 88:11520-4. doi:10.1073/pnas.88.24.11520

55. Boasso A, Herbeuval JP, Hardy AW, Winkler C, Shearer GM. Regulation of indoleamine 2,3-dioxygenase and tryptophanyl-tRNA-synthetase by CTLA-4-Fc in human CD4+ T cells. Blood (2005) 105:1574-81. doi:10.1182/ blood-2004-06-2089

56. Malleret B, Maneglier B, Karlsson I, Lebon P, Nascimbeni M, Perie L, et al. Primary infection with simian immunodeficiency virus: plasmacytoid dendritic cell homing to lymph nodes, type I interferon, and immune suppression. Blood (2008) 112:4598-608. doi:10.1182/blood-2008-06-162651

57. Carlin JM, Borden EC, Sondel PM, Byrne GI. Interferon-induced indoleamine 2,3-dioxygenase activity in human mononuclear phagocytes. JLeukoc Biol (1989) 45:29-34.

58. Orabona C, Pallotta MT, Volpi C, Fallarino F, Vacca C, Bianchi R, et al. SOCS3 drives proteasomal degradation of indoleamine 2,3-dioxygenase (IDO) and antagonizes IDO-dependent tolerogenesis. Proc Natl Acad Sci U S A (2008) 105:20828-33. doi:10.1073/pnas.0810278105

59. Moutsopoulos NM, Vazquez N, Greenwell-Wild T, Ecevit I, Horn J, Orenstein J, et al. Regulation of the tonsil cytokine milieu favors HIV susceptibility. J Leukoc Biol (2006) 80:1145-55. doi:10.1189/jlb.0306142

60. Akhtar LN, Qin H, Muldowney MT, Yanagisawa LL, Kutsch O, Clements JE, et al. Suppressor of cytokine signaling 3 inhibits antiviral IFN-beta signaling to enhance HIV-1 replication in macrophages. J Immunol (2010) 185:2393-404. doi:10.4049/jimmunol.0903563

61. Huang L, Ou R, Rabelo de Souza G, Cunha TM, Lemos H, Mohamed E, et al. Virus infections incite pain hypersensitivity by inducing indoleamine 2,3 dioxygenase. PLoS Pathog (2016) 12:e1005615. doi:10.1371/journal. ppat. 1005615
62. Chase AJ, Sedaghat AR, German JR, Gama L, Zink MC, Clements JE, et al. Severe depletion of CD4+ CD25+ regulatory $\mathrm{T}$ cells from the intestinal lamina propria but not peripheral blood or lymph nodes during acute simian immunodeficiency virus infection. J Virol (2007) 81:12748-57. doi:10.1128/ JVI.00841-07

63. Alammar L, Gama L, Clements JE. Simian immunodeficiency virus infection in the brain and lung leads to differential type I IFN signaling during acute infection. J Immunol (2011) 186:4008-18. doi:10.4049/ jimmunol.1003757

64. Lob S, Konigsrainer A, Rammensee HG, Opelz G, Terness P. Inhibitors of indoleamine-2,3-dioxygenase for cancer therapy: can we see the wood for the trees? Nat Rev Cancer (2009) 9:445-52. doi:10.1038/nrc2639

65. Gendelman HE, Zheng J, Coulter CL, Ghorpade A, Che M, Thylin M, et al. Suppression of inflammatory neurotoxins by highly active antiretroviral therapy in human immunodeficiency virus-associated dementia. J Infect Dis (1998) 178:1000-7. doi:10.1086/515693

66. Chen J, Shao J, Cai R, Shen Y, Zhang R, Liu L, et al. Anti-retroviral therapy decreases but does not normalize indoleamine 2,3-dioxygenase activity in HIV-infected patients. PLoS One (2014) 9:e100446. doi:10.1371/journal. pone. 0100446

67. Boasso A, Vaccari M, Fuchs D, Hardy AW, Tsai WP, Tryniszewska E, et al. Combined effect of antiretroviral therapy and blockade of IDO in SIVinfected rhesus macaques. J Immunol (2009) 182:4313-20. doi:10.4049/ jimmunol.0803314

68. Vaccari M, Boasso A, Fenizia C, Fuchs D, Hryniewicz A, Morgan T, et al. Fatal pancreatitis in simian immunodeficiency virus SIV(mac251)-infected macaques treated with 2',3'-dideoxyinosine and stavudine following cytotoxic-T-lymphocyte-associated antigen 4 and indoleamine 2,3-dioxygenase blockade. J Virol (2012) 86:108-13. doi:10.1128/JVI.05609-11

69. Agaugue S, Perrin-Cocon L, Coutant F, Andre P, Lotteau V. 1-Methyltryptophan can interfere with TLR signaling in dendritic cells independently of IDO activity. J Immunol (2006) 177:2061-71. doi:10.4049/ jimmunol.177.4.2061

70. Uyttenhove C, Pilotte L, Theate I, Stroobant V, Colau D, Parmentier N, et al. Evidence for a tumoral immune resistance mechanism based on tryptophan degradation by indoleamine 2,3-dioxygenase. Nat Med (2003) 9:1269-74. doi:10.1038/nm934

71. Routy JP, Routy B, Graziani GM, Mehraj V. The kynurenine pathway is a double-edged sword in immune-privileged sites and in cancer: implications for immunotherapy. Int J Tryptophan Res (2016) 9:67-77. doi:10.4137/IJTR. S38355

72. Vacchelli E, Aranda F, Eggermont A, Sautes-Fridman C, Tartour E, Kennedy EP, et al. Trial watch: IDO inhibitors in cancer therapy. Oncoimmunology (2014) 3:e957994. doi:10.4161/21624011.2014.957994

Conflict of Interest Statement: The authors declare that the research was conducted in the absence of any commercial or financial relationships that could be construed as a potential conflict of interest.

Copyright (c) 2016 Drewes, Croteau, Shirk, Engle, Zink and Graham. This is an open-access article distributed under the terms of the Creative Commons Attribution License (CC BY). The use, distribution or reproduction in other forums is permitted, provided the original author(s) or licensor are credited and that the original publication in this journal is cited, in accordance with accepted academic practice. No use, distribution or reproduction is permitted which does not comply with these terms. 